Katiusci Lehnhard Machado (iD) https://orcid.org/0000-0003-0625-0927

Carmem Lúcia Colomé Beck ${ }^{\mathrm{b}}$ (iD) https://orcid.org/0000-0001-9060-1923

Cláudia Maria Perrone ${ }^{\mathrm{c}}$ (iD) https://orcid.org/0000-0002-3840-4575

Alexa Pupiara Flores Coelho ${ }^{d}$ (iD) https://orcid.org/0000-0002-9117-5847

Raíssa Ottes Vasconcelos ${ }^{d}$

(iD) https://orcid.org/0000-0002-6526-2197

a Universidade Federal de Santa Maria, Departamento de Pós-Graduação em Psicologia. Santa Maria, RS, Brasil.

b Universidade Federal de Santa Maria, Departamento de Enfermagem. Santa Maria, RS, Brasil.

'Universidade Federal de Santa Maria, Centro de Ciências Sociais e Humanas, Departamento de Psicologia. Santa Maria, RS, Brasil.

dUniversidade Federal de Santa Maria, Departamento de Enfermagem. Santa Maria, RS, Brasil.

Contato:

Katiusci Lehnhard Machado

E-mail:

klehnhard@yahoo.com.br

As autoras declaram que o trabalho não foi subsidiado e que não há conflitos de interesses.

As autoras informam que o trabalho não foi apresentado em eventos científicos.

Trabalho baseado na dissertação de Mestrado intitulada Organização do trabalho e a mobilização subjetiva de trabalhadores de um centro de atenção psicossocial, álcool e drogas, de Katiusci Lehnhard Machado, defendida em 2014 na Universidade Federal de Santa Maria, RS, Brasil.

\section{Mobilização subjetiva de trabalhadores de um Centro de Atenção Psicossocial Álcool e Drogas: intervenção em saúde do trabalhador por meio da clínica psicodinâmica do trabalho}

\author{
Subjective mobilization of workers from a Psychosocial Care \\ Center for Alcohol and Drugs: intervention in worker's health \\ through the psychodynamic work clinic
}

\section{Resumo}

Objetivo: conhecer as formas de mobilização subjetiva utilizadas pelos trabalhadores de um Centro de Atenção Psicossocial Álcool e Drogas a partir de uma pesquisa de intervenção. Métodos: pesquisa qualitativa que utilizou como metodologia a Clínica do Trabalho. Foram realizadas 5 sessões grupais com 16 trabalhadores de saúde mental do referido centro. Para interpretar os achados, utilizou-se a análise de conteúdo temática. Resultados: os trabalhadores não se sentem valorizados nem apoiados pelos superiores hierárquicos em aspectos que dão sentido ao seu trabalho.Isto produz implicações à construção da identidade e ao engajamento da atividade que realizam. Diante disso, os trabalhadores utilizam estratégias de defesa e deflagram a mobilização subjetiva. Os espaços de discussão contribuem para diminuir a angústia, amenizar e suportar o desgaste do trabalhador. Por meio da cooperação obtêmse vivências de prazer nas relações socioprofissionais. Conclusão: a cooperação e a agregação do coletivo de trabalho representam o principal movimento de mobilização subjetiva dos trabalhadores.

Palavras-chave: serviços comunitários de saúde mental; serviços de saúde mental; saúde do trabalhador.

\begin{abstract}
Objective: to know about the subjective mobilization forms used by the workers from a Psychosocial Care Center for Alcohol and Drugs. Methods: qualitative intervention research employing the Work Clinic methodology. Five group sessions were held, involving sixteen workers from the center mental health service. Thematic content analysis was carried out to interpret the findings. Results: workers do not feel valued and supported by their hierarchic superiors in aspects that give meaning to their work. This interferes in the construction of their identity and in their engagement in the activity they are involved in. To cope with this situation, workers adopt defensive strategies and trigger subjective mobilizations. Discussion spaces contribute to decrease workers' anxiety, relieve exhaustion and help them to stand it. Through cooperation, pleasurable experiences are obtained in socio-professional relations. Conclusion: cooperation and aggregation of the work collective represent the workers' main subjective mobilization movement.
\end{abstract}

Keywords: mental health community services; mental health services; occupational health. 


\section{Introdução}

As transformações aceleradas no mundo do trabalho nos últimos anos têm provocado mudanças importantes no trabalho em saúde, especialmente em relação aos processos produtivos, ao perfil do trabalhador e às condições de trabalho ${ }^{1}$. Na área da saúde mental, também ocorrem mudanças de caráter organizativo, com a institucionalização da reforma psiquiátrica brasileira ${ }^{2}$.

A reforma psiquiátrica configurou transformações em relação à concepção de sofrimento psíquico, no modo de compreender, intervir, tratar e se relacionar com esse sofrimento ${ }^{3}$. Isso provocou a implementação de um modelo de atenção centrado nas necessidades singulares de cada pessoa, no estímulo à reinserção social, na vida familiar e comunitária.

Nessa direção, foram criados os Centros de Atenção Psicossocial (CAPS), que têm sido a principal estratégia de consolidação da reforma psiquiátrica. Eles têm contribuído para transformações nos espaços de atuação profissional, os quais não têm mais a centralidade no manicômio ${ }^{3}$. Podem ser classificados em I, II, III, AD (álcool e drogas) e i (infantil), conforme a abrangência da população atendida e o horário de funcionamento. Os CAPS $\mathrm{AD}$ atendem adultos, crianças e adolescentes que fazem uso abusivo de álcool e outras drogas, com necessidades de cuidados clínicos contínuos. Atualmente o CAPS é um componente estratégico na rede de atenção psicossocial ${ }^{2}$.

Diante deste cenário, os trabalhadores vivenciam no cotidiano do trabalho a transição paradigmática do modo asilar para o modo psicossocial ${ }^{4}$. Assim, eles são convocados a fazer parte de um movimento de transformação, cujo produto do trabalho é a produção de cuidado que desenvolva sujeitos autônomos a partir de relações dialógicas.

Assim, o fortalecimento de espaços coletivos para analisar e refletir sobre práticas profissionais, conflitos e diferentes pressões oriundas do contexto laboral torna-se importante ${ }^{5}$. A adoção de novos saberes, tecnologias e metodologias de trabalho requer do trabalhador um investimento psíquico, uma mobilização subjetiva.

Neste sentido, destaca-se a psicodinâmica do trabalho, corrente francesa que considera as interfaces entre trabalho e saúde mental, sendo uma das abordagens da Clínica do Trabalho. Para a psicodinâmica, o trabalho é considerado importante na vida dos sujeitos, e sua investigação busca problematizar o modo como a identidade e saúde psíquica dos sujeitos se relaciona com a organização do trabalho ${ }^{6}$. O foco da relação trabalho-saúde, de acordo com essa corrente, está na dinâmica prazer-sofrimento, na relação do trabalho entre corpo e mente do trabalhador e na maneira como homem e trabalho interagem e se modificam no cotidiano laboral.

As estratégias de defesa são utilizadas diante de um trabalho que gera sofrimento. As mais frequentes são a banalização, negação e racionalização. Elas podem contribuir para tornar o sofrimento suportável, e o trabalho, possível ${ }^{7}$. No entanto, não modificam sua realidade, apenas o tornam operativo. Por outro lado, o trabalhador pode mudar a realização do trabalho se usar a mobilização subjetiva ${ }^{8}$, pois permite sua ressignificação por meio do reconhecimento, do uso da inteligência prática e da cooperação, em um espaço público e coletivo de discussão, onde exista confiança e solidariedade ${ }^{9}$. Uma das características da mobilização subjetiva é a capacidade dos sujeitos de sentir, pensar e inventar criar soluções para realizar o trabalho ${ }^{10}$.

A mobilização subjetiva sob a perspectiva da psicodinâmica do trabalho com trabalhadores de CAPS permanece pouco explorada na pesquisa em psicologia. Estudos apontam dificuldades que potencializam o desgaste do trabalhador, como falta de redes sociais de apoio, dinâmica de trabalho polivalente, falta de recursos humanos, precariedade de vínculos empregatícios, dificuldade de comunicação e atuação intersetorial ${ }^{5,9,11}$. Portanto, a aplicação da psicodinâmica do trabalho na produção do conhecimento sobre trabalhadores de CAPS AD é necessária, tendo em vista o compromisso ético com a saúde e a relação dinâmica entre o trabalho e os modos de subjetivação dos trabalhadores ${ }^{12}$. Sob esta perspectiva, o objetivo deste estudo é conhecer as formas de mobilização subjetiva utilizadas pelos trabalhadores de um $\mathrm{AD}$ a partir de uma pesquisa-intervenção.

\section{Métodos}

Trata-se de um estudo qualitativo que utiliza o referencial teórico-metodológico da psicodinâmica do trabalho aplicado em uma Clínica do Trabalho, por meio da escuta clínica, na qual o pesquisador favorece a circulação da fala e a escuta do trabalhador sobre suas experiências, elaboradas no espaço de reflexão do próprio trabalho ${ }^{13}$, tomando-se como operadores a elaboração psíquica, a observação clínica e a interpretaçãa ${ }^{14}$.

Destaca-se que, para haver produção de sentido e elaboração de vivências subjetivas relacionadas ao trabalho, não basta o pesquisador ouvir os trabalhadores, é necessário escutá-los. Neste sentido, a psicodinâmica do trabalho propõe sessões coletivas, nas quais os trabalhadores analisam suas vivências, e os pesquisadores propõem hipóteses de discussão ${ }^{15}$. 
Esse método pressupõe uma ação transformadora na situação investigada, que implica engajamento coletivo de trabalhadores como corresponsáveis pela ação ${ }^{16}$. Ainda, o pesquisador deve analisar as situações levantadas, enquanto as soluções e estratégias encontradas pertencem aos próprios trabalhadores ${ }^{17}$.

O cenário deste estudo foi um CAPS AD localizado em um município no Sul do Brasil, o qual prestava serviços extra-hospitalares e abertos de base territorial. Também disponibilizava atendimento interdisciplinar a cerca de duzentos e cinquenta mil usuários de uso abusivo de álcool e outras drogas, com sofrimento psíquico, tanto adolescentes e adultos quanto idosos.

Participaram deste estudo trabalhadores formados no ensino fundamental, médio e superior deste CAPS AD. Foram incluídos indivíduos de ambos os gêneros que vivenciavam o processo de trabalho no período da pesquisa, e foram excluídos os que estavam afastados. Do total de 18 profissionais, a amostra foi composta por 16, sendo 4 homens e 12 mulheres, incluindo-se: técnicos em saúde mental; enfermeiros; assistentes sociais; psicólogos; agente de serviços gerais; redutores de danos; profissionais de uma Residência Multiprofissional em Saúde e acadêmicos dos cursos de serviço social e psicologia de uma Instituição de Ensino Superior pública e outra privada. Durante a produção de dados, um trabalhador estava de férias, outro em licença-interesse, e nenhum se recusou a participar. Esse período de produção durou cinco semanas, sendo 14 a média de participantes.

A produção de dados incluiu, primeiramente, análise documental, na qual foram consultados dois arquivos, um contendo as atas de todas as reuniões do serviço, e outro, os projetos propostos desde sua implementação; essa etapa durou um mês. Além disso, também foram feitas observações do trabalho por oito horas semanais, durante três meses. A análise documental e as observações contribuíram para reunir elementos sobre organização do trabalho. Nessa etapa, foram obtidas as primeiras informações e impressões sobre o campo da pesquisa ${ }^{14}$. Elaborou-se também um diário de campo com observações sobre a pesquisa, análise documental e observações iniciais, somadas aos relatos dos encontros e ao memorial.

A segunda etapa da produção de dados tratou das sessões grupais, nas quais foi aplicada a Clínica do Trabalho. Contou-se com duas assistentes de pesquisa anteriormente capacitadas pela pesquisadora, e foram realizadas cinco sessões no CAPS AD, cada uma de aproximadamente uma hora e meia. A condução seguiu as recomendações de Mendes e Araújo ${ }^{14}$ em relação às etapas que o pesquisador deve considerar no desenvolvimento das sessões grupais.

Na primeira sessão foi discutida a demanda de pesquisa, pois precisou ser validada pelo grupo participante. Esclareceu-se a dinâmica dos encontros, a fim de que os trabalhadores entendessem o espaço grupal como local de fala sobre o que acreditavam ser importante sobre as vivências de seu trabalho. Além disso, procedeu-se uma questão disparadora: "Como é o trabalho aqui neste serviço?".

As sessões grupais buscaram problematizar a realidade do trabalho e viabilizar reflexões e críticas sobre ele. A consolidação da pesquisa e da ação, no coletivo, é demonstrada quando os trabalhadores formulam ideias não organizadas conscientemente ${ }^{14}$.

O memorial, documento descritivo que contém interpretações do que Dejours ${ }^{17}$ denomina de "coletivo de clínicos", foi construído ao final de cada sessão, sendo lido para o grupo no encontro seguinte ${ }^{12}$. $\mathrm{O}$ coletivo de pesquisa, ou seja, seus participantes e pesquisadores, decidiram que o relato seria lido, discutido e analisado no encontro seguinte, pois se acreditou que, desse modo, o tornaria mais relevante. Os memoriais foram denominados de "relato do encontro".

Os primeiro, segundo e terceiro relatos foram descritivos, contendo um resumo do que os trabalhadores traziam como vivências de trabalho. Nessas sessões, discorreu-se sobre temáticas do trabalho e buscou-se construir a demanda clínica. No início da quarta sessão, cinco questões disparadoras foram levantadas para o coletivo, as quais representavam queixas e discussões apresentadas pelo grupo. Esta sessão se iniciou com a afirmação das próprias queixas e permitiu um espaço de crítica sobre o trabalho.

Durante a quarta sessão, houve a restituição, ou seja, a retomada do tema discutido na sessão anterior e concretizada no início das sessões. É tida como espaço para acrescentar, discordar, reiterar e propor ações para resolver conflitos expostos nas sessões ${ }^{14}$.

O relatório final foi apresentado na quinta sessão, tendo como base o relato dos encontros e contendo a discussão dos temas dos encontros anteriores, os quais haviam sido validados com o coletivo. Destaca-se que, associando-se o relatório final às observações clínicas da pesquisadora, um novo espaço de discussão foi criado e, com isso, novas interpretações foram feitas pelo grupo.

Os dados das sessões, isto é, as falas dos participantes, foram audiogravados com anuência de todos e posteriormente transcritos na íntegra por meio do Express Scribe Transcription Software. Para analisar o material, foi utilizada a técnica da análise temática de conteúdo, desenvolvida em três etapas: 
pré-análise; exploração do material; e análise dos dados e interpretação ${ }^{18}$.

Destaca-se que esta pesquisa está em conformidade com a Resolução ${ }^{\circ} 10 / 2012$, do Conselho Federal de Psicologia (CFP), e com a Resolução $n^{\circ}$ 466/12, do Conselho Nacional de Saúde (CNS) ${ }^{19}$. Todos os participantes foram esclarecidos quanto à pesquisa e assinaram o Termo de Consentimento Livre e Esclarecido, e a pesquisa foi aprovada pelo Comitê de Ética em Pesquisa local, com o parecer $\mathrm{n}^{\mathrm{o}} 628.751$.

\section{Resultados e discussão}

Serão apresentados os resultados referentes à mobilização subjetiva, a qual inclui inteligência prática, reconhecimento, espaço de discussão e cooperação. Outra forma empregada diante do sofrimento são estratégias defensivas, que podem estabilizar temporariamente o trabalhador, tornando o sofrimento suportável, e o trabalho, possível ${ }^{7}$.

Para usar estes dispositivos, os trabalhadores encontram caminhos e dificuldades. Sendo assim, na primeira categoria temática, "Burocracia, não reconhecimento e invisibilidade: vivências de sofrimento no CAPS Álcool e Drogas”, foram descritas as dificuldades impostas, principalmente pela organização do trabalho, as quais culminam em sofrimento e justificam a necessidade de posturas de enfrentamento dos trabalhadores. Já a segunda categoria, "Das estratégias de defesa à mobilização subjetiva: a cooperação como caminho", discute como os sujeitos deflagram estratégias de defesa e mobilização subjetiva no cotidiano do trabalho em resposta ao sofrimento.

\section{Burocracia, não reconhecimento e invisibilidade: vivências de sofrimento no CAPS AD}

O reconhecimento no campo do trabalho existe dentro do coletivo, sendo entendido como gratificação ou constatação pelo processo de julgamento, o qual pode ser específico, como o julgamento de utilidade e o de beleza. $\mathrm{O}$ primeiro diz respeito à utilidade da contribuição técnica, social e econômica do sujeito, sendo proferido pela hierarquia, pelos subordinados ou clientes e, neste caso, pelos usuários. O segundo trata da qualidade, singularidade e originalidade de uma tarefa, proferido pelos pares, por quem conhece bem as regras de ofício e o estado da arte $^{7}$.

O reconhecimento da utilidade do trabalho é apontado como retribuição advinda das pessoas quede quem vivencia ou conhece o trabalho no CAPS. Veja-se a seguinte fala:
Bacana quando alguém pede para estar aqui porque "eu conheço", ou já esteve como estagiário e acabou voltando porque acredita e quer estar junto nisso.

O pessoal fala [...] eu quero trabalhar com vocês.

Por um lado, a experiência do reconhecimento surge quando as pessoas que conhecem intimamente o cotidiano de trabalho vivenciaram seu fazer ou as dificuldades e estratégias de enfrentamento dos trabalhadores, valorizando o engajamento e a proposta de trabalho do CAPS. Assim, o reconhecimento advém de antigos colegas que conhecem bem seu fazer e valorizam sua utilidade.

O reconhecimento também é evidenciado por instituições que não dividem diretamente o cotidiano de trabalho, mas promovem condições favoráveis à obtenção de prazer. Como efeito dessa retribuição, o trabalhador sente-se seguro sobre sua atividade, possibilitando seu sentimento de realização e engajamento, conforme a fala a seguir:

A sensação é bacana quando [...] outros lugares o pessoal aponta: vocês estão fazendo uma coisa interessante [...]. Quem vem de fora consegue dizer, a gente se fortalece. Estamos indo por uma linha certa!

Para obter prazer no trabalho, ressignificar o sofrimento e transformá-lo em realização, é necessário que o trabalhador se engaje e, para se engajar, é preciso reconhecimento. E essa dinâmica de engajamento decorre da seguinte situação: o trabalhador contribui para o trabalho, e a organização retribui (de maneira material e/ou simbólica) reconhecendo seu esforço ${ }^{20}$. Assim, o trabalho torna-se prazeroso e o trabalhador consegue se engajar.

É possível compreender que o reconhecimento, oriundo do olhar do outro, é considerado fundamental para engajar o trabalhador. Contudo, os participantes citam que a burocracia limita o desejo em ser reconhecido como alguém que usa seus conhecimentos nas propostas de trabalho e, portanto, deveria ser notado:

\footnotetext{
Tu desejas lutar e construir coisas, mas aí existe uma burocracia que está a serviço de matar o teu desejo. Desejo de construir coisas que tu sabes que, de alguma forma, podem dar um retorno melhor, acreditar num processo que é atender a saúde do outro, não separada da tua.
}

A burocracia é traduzida em uma gestão que se mostra pouco apoiadora das práticas do serviço. Isto se expressa tanto pela falta de material psicopedagógico e condições na estrutura física como nas ações psicossociais com os usuários, e como consequência a retribuição aos trabalhadores é dificultada. Desse modo, um dos poucos momentos em que os participantes se questionam é quando se deparam com a 
falta do olhar do outro (da gestão) e com as implicações disso para sustentar o engajamento e a mobilização da sua subjetividade no trabalho.

O trabalhador deseja se engajar na atividade, mas muitas vezes o excesso de burocracia exigido desestimula seu potencial. Com isso, ele perde a liberdade para transformar o trabalho e colocar sua marca pessoal no exercício do ser ${ }^{14}$. Os trabalhadores referem que o investimento no tratamento do usuário, desenvolvendo seu protagonismo e sua autonomia, não resulta em reconhecimento do seu engajamento, especialmente quando há esforço para realizar uma atividade inovadora no cenário municipal.

Embora o trabalho seja construído na perspectiva de rede, eles acreditam viver a mesma exclusão dos usuários pois, conforme a fala de um participante, ainda há muito preconceito na sociedade e nos serviços de saúde. Ele referencia de forma irônica um grafite construído coletivamente pelos usuários na fachada do CAPS, criticado posteriormente pela gestão da saúde:

Parece que tem que ter este serviço [...] eu quero que a sociedade veja que as pessoas fazem uma coisa bonitinha aqui. E quando aparece por meio de um grafite, daí a coisa apareceu, então, existe mesmo um usuário de drogas e ele apareceu ali ó, na fachada, sabe? Existe um serviço, mas não é para aparecer muito.

Os trabalhadores esperam uma retribuição simbólica e que os outros julguem seu trabalho, avaliem seu interesse e engajamento, e reconheçam o valor social do que fazem ${ }^{21}$. Em outra pesquisa, o sentimento mais enfatizado foi o ressentimento pela falta de reconhecimento e valorização, tanto pela gestão como pelos usuários da instituição ${ }^{22}$. Quando a gestão e os colegas de outros serviços não conseguem valorizar no trabalhador o ato de pensar, sua experiência, dedicação e engajamento cognitivo, afetivo e físico, não se gratifica nem se constata seu empenho, tendo em vista que o reconhecimento é proporcional às contribuições, aos esforços ${ }^{7}$.

Ele não é só tarefeiro (o trabalhador), ele pensa também. Quanto mais tu pensas, falas, tu és sinônimo de ameaça.

Os trabalhadores afirmaram que há um sujeito pensante no ato de trabalhar, o qual é barrado pela organização do trabalho. No estudo em questão, essa organização distancia o trabalho prescrito do real, ainda apresentado em um modelo de gestão que dificulta o aparecimento da criatividade. Dessa forma, não há espaço para criar, negociar, constituir e consolidar o coletivo, predominando as defesas ${ }^{14}$.

O sofrimento patogênico e as estratégias de defesa que visam a negação ou o controle do sofrimento, aparecerão nas situações em que não há reconhecimento, quando o trabalhador não consegue construir sentido nem prazer no que realiza ${ }^{16}$. Portanto, evidencia-se a necessidade de estratégias de defesa capazes de contrabalancear o sofrimento. Porém, a mobilização subjetiva se mostra como caminho de escolha para que os indivíduos consigam modificar as situações disparadoras de sofrimento e transformar a organização do trabalho, construindo uma experiência laboral prazerosa e plena.

\section{Das estratégias de defesa à mobilização subjetiva: a cooperação como caminho}

Diante do sofrimento instaurado pelas dificuldades de desempenhar seu ofício, primeiramente os trabalhadores utilizam estratégias de defesa, definidas como "rotas de fuga", a partir das quais são capazes de bloquear sentimentos, mantendo-se em equilíbrio $^{17}$. As estratégias de controle, por meio de mecanismos de racionalização, são utilizadas ao perceberem a precariedade da gestão:

A gente pede um administrativo (funcionário na função administrativa), mas não tem. A gente sofre um pouco, mas... A gente tem um município de gestão superprecária, e isso reflete direto na gente [...]. Tem que aprender a se mover nesta gestão, que é muito fragilizada.

Eles também utilizam algumas estratégias de resistência para enfrentar dificuldades e imprevistos do real do trabalho:

\begin{abstract}
A gente veio para esta casa e não tinha corrimão. A gente não vai atender na parte de baixo enquanto não tiver corrimão. Ah! Como que não vai ter atendimento o dia inteiro? O pessoal não vai descer escada sem ter corrimão.
\end{abstract}

Esta postura possibilita ao trabalhador encontrar estratégias para enfrentar o sofrimento de modo criativo e mudar situações que provocam sofrimento, o qual se centra na compreensão de a gestão não proporcionar condições favoráveis de trabalho. $\mathrm{O}$ uso da inteligência prática baseia-se no conhecimento adquirido pelo trabalhador considerando que ninguém sabe mais sobre seu trabalho do que ele mesmo, e isto acontece por sua experiência no fazer do trabalho. Os trabalhadores apontaram que, perante situações já conhecidas que possam ter causado sofrimento, eles foram aprendendo as melhores maneiras de enfrentá-las:

A gente, no início, bateu muito de frente com essas coisas [com a gestão]. A gente foi aprendendo como é que vai fazer para não bater de frente e compor [...] Eu aprendi a não sofrer tanto com certos processos de gestão que acabam sendo mais lentos. 
Vale destacar que a experiência adquirida pelos trabalhadores possibilita o entendimento de que uma atuação permeada pelo confronto com a organização do trabalho não traz benefícios. Essa conclusão é possível a partir da análise do trabalho real e concreto como lugar de construção da identidade do trabalhador. Assim, considera-se que, para transformar um trabalho que faz sofrer (confronto) em um trabalho prazeroso (composição), é necessário que a organização do trabalho propicie alguma liberdade para mudanças e mobilização do trabalhador, guiadas pela cooperação, por momentos de discussão e pelo uso de sua inteligência prática ${ }^{24}$.

A gente chegou em um momento e teve que fazer escolhas mais claras. Vamos escolher, primeiramente, fazer alguma atuação em que a gente não se detone muito [...]. E se tiver que ter um respaldo negativo na gestão, vamos cuidar para que não seja contra, de nos destruir enquanto serviço, de querer fechar.

Eles demonstram que essa tomada de decisão resultou em proteção do coletivo, e não em prazer, buscando muito mais se preservar contra o aniquilamento do que imprimir seu potencial criativo para transformar a realidade. Observa-se o uso de defesas de adaptação e de exploração, as quais se relacionam à submissão aos desejos da organização. Com isso, o sujeito nega seu sofrimento e se adapta a ele $^{25}$.

Os trabalhadores sinalizaram que a troca e o apoio entre colegas são dispositivos importantes para resolver situações de sofrimento. $\mathrm{O}$ apoio e o uso do espaço coletivo para solucionar problemas e exteriorizar sentimentos se mostra válido para eles:

Eu acho que todo mundo tenta resolver aqui dentro.

[...] Eu sempre trago para os meus colegas, tanto individual como na reunião de equipe. [...]. E falo dos seus sentimentos: "Olha, estou sofrendo com tal caso".

Para os trabalhadores, construiu-se no CAPS um ambiente de compartilhamento das situações de trabalho, reconhecido por seu potencial de apoio entre colegas. Estudo aponta que o trabalho em equipe nos CAPS implica ações que potencializam o trabalho coletivo e formas dialógicas de organização ${ }^{26}$. Assim, criar um espaço de discussão é importante, pois dá voz ao sofrimento dos trabalhadores e potencializa a mobilização subjetiva do coletivo para elaborar regras sobre o fazer e o viver no espaço de trabalho ${ }^{14}$.

Sendo assim, evidencia-se que os participantes transitam das estratégias de defesa à mobilização subjetiva, uma vez que, além de se protegerem do sofrimento, estabelecem estratégias para modificar a realidade, encontrando na agregação do coletivo de trabalho o principal dispositivo para isso.
O trabalho no CAPS exige dos trabalhadores que sua atividade seja realizada em conjunto, como um espaço coletivo de ação e reflexão de suas práticas profissionais. Salienta-se também que as transformações do modelo de atenção preconizado pela reforma psiquiátrica precisam ser compartilhadas, pois são vivenciadas pelo trabalhador do CAPS como fator que produz tanto prazer quanto sofrimento ${ }^{23}$.

As dificuldades enfrentadas pelos trabalhadores os levaram a criar estratégias de cooperação. Eles relatam que uma delas é o desenvolvimento de relações solidárias, com o apoio do colega:

O trabalho aqui tem problemas, sim, mas sempre tem alguém para te apoiar [...]. Se tiver alguma coisa que está me afligindo, sempre tem alguém para te ajudar a responder.

Diante dos problemas, a relação entre colegas produz segurança e confiança, pois os participantes relatam disponibilidade para investir nesta relação. Como efeito, produz-se cumplicidade, o que não ocorre estabelecendo regras no trabalho, mas sim espontaneamente. Dessa forma, é preciso envolvimento da confiança e do espaço de discussão. Destaca-se que a confiança, a ética e a visibilidade são necessárias para que as pessoas possam cooperar ${ }^{12}$.

A capacidade de os trabalhadores construírem laços afetivos favorece um espaço para a mobilização subjetiva, para ressignificar o sofrimento e agir sobre a organização do trabalho, pois evidencia-se investimento do corpo e afeto do trabalhador. Eles relatam que uma situação de difícil resolução no serviço, que gerou medo, pôde ser superada por meio da cooperação, da solidariedade e da confiança, conforme os seguintes depoimentos:

Agora pensei a coisa de se ajudar: desde o momento que eu e a colega quase apanhamos, eu fiquei com medo, mas estávamos as duas lá, juntas.

Porque uma pessoa sozinha não daria conta. Uma equipe inteira se divide.

A equipe pegar junto produz saúde para o usuário [...]. E para nós, também.

A produção de saúde relatada pelos trabalhadores pode resultar da ação do grupo, e sua mobilização subjetiva é o meio de construir o trabalho coletivo, embasado na solidariedade, essencial para o trabalho, favorecendo vivências de prazer $^{27}$. A mobilização subjetiva e as estratégias defensivas são fundamentais para a saúde mental no trabalho, e o apoio da equipe é ponto central para a estruturação subjetiva do sujeito para levá-lo a um trabalho mais saudável. Na experiência do viver junto, do enfrentar a resistência do real, os trabalhadores constroem um sentido para o trabalho, para o sofrimento, o que 
pode favorecer seu engajamento. A mobilização subjetiva permite uma operação simbólica, o resgaste do sentido do trabalho.

\section{A Clínica do Trabalho como caminho para mediar a mobilização subjetiva}

No intervalo da primeira para a segunda sessão, os participantes apontaram o espaço da Clínica do Trabalho como movimento importante de pensar o cotidiano do trabalho no serviço. No entanto, o grupo não conseguiu discutir, naquele momento, possibilidades de deliberações que indicassem uma mobilização para a ação dos aspectos apontados como sofrimento no contexto do trabalho.

Houve consenso em um momento subsequente de retomada das discussões possibilitadas por meio da Clínica do Trabalho, quatro meses depois. Neste encontro, o grupo do CAPS conseguiu passar do espaço de discussão para o das deliberações, componente essencial para a mobilização subjetiva. Isto confirma que a mobilização subjetiva consiste em um movimento complexo, do qual depende o engajamento do coletivo, o diálogo compartilhado e a ressignificação das vivências de prazer e sofrimento, por meio do espaço da fala. Sendo assim, a aplicação da Clínica do Trabalho neste estudo se mostrou válida, pois atuou como mediador fundamental para os trabalhadores refletirem sobre seu trabalho.

\section{Conclusão}

A Clínica do Trabalho, que representa uma oportunidade de promover a mobilização subjetiva dos trabalhadores, ajudou a desvelar a organização do trabalho, as vivências de prazer e sofrimento e, com isso, conhecer as estratégias de enfrentamento dos trabalhadores diante das situações do trabalho. Ao mesmo tempo, as sessões possibilitaram ao grupo reafirmar o espaço de discussão como fundamental para falar e significar suas vivências. Revelou-se, assim, um espaço de cooperação para o compartilhar dessas vivências, na busca por recursos e destinos para amenizar o sofrimento.

A forma como os participantes discutiam seus conflitos permite o entendimento de que, apesar das dificuldades no desenvolvimento do trabalho, encontravam nas relações socioprofissionais e na união da equipe formas de se manter fortalecidos como coletivo. Salienta-se que a cooperação foi instituída como regra de trabalho e protege os trabalhadores das pressões exercidas pela organização do trabalho.

Faltam espaços de análise sobre o trabalho capazes de auxiliar os trabalhadores a fortalecer sua mobilização subjetiva. Recomenda-se a replicação de novas metodologias de intervenção com eles, com destaque para a Clínica do Trabalho, tendo em vista sua potencialidade para promover a saúde mental no trabalho.

As limitações do estudo foram percebidas durante a implicação dos trabalhadores com a transformação das situações que apontavam como problemas do cotidiano de trabalho, pois por muito tempo o grupo apresentou-se resistente à mudança de posição subjetiva. $\mathrm{Na}$ última sessão, produziram sentido a suas falas, buscando descrever vivências de sofrimento. Para tanto, acredita-se que, nas pesquisas, utilizando-se a Clínica do Trabalho, é importante que se flexibize o número de sessões grupais. Ainda, aponta-se que a condução da pesquisa se deu por um clínico com experiência na escuta e na interpretação, o que contribui para a mobilização subjetiva dos trabalhadores.

\section{Contribuições de autoria}

Machado KL, Beck CLC e Perrone CM participaram da concepção do projeto, levantamento, análise e interpretação dos resultados e, com Coelho APF e Vasconcelos RO, elaboraram, revisaram e aprovaram a versão final do manuscrito. Todas assumem publicamente a responsabilidade pelo trabalho desenvolvido e publicado.

\section{Referências}

1. Merlo ARC, Mendes AMB. Perspectivas do uso da psicodinâmica do trabalho no Brasil: teoria, pesquisa e ação. Cad Psicol Soc Trab. 2009;12(2):141-56.

2. Brasil. Ministério da Saúde. Portaria n ${ }^{0} 3.088 / 2011$. Brasília, DF: Ministério da Saúde [internet]; 2011 [citado 10 jan 2018]. Disponível em: http:// bvsms.saude.gov.br/bvs/saudelegis../gm/2011/ prt3088_23_12_2011_rep.html
3. Ribeiro MC. Psychosocial care center workers in Alagoas, Brazil: interstices of new practices. Interface (Botucatu). 2015;19(52):95-107.

4. Costa LA, Almeida SC, Assis MG. Epistemic reflections on Occupational Therapy in Mental Health. Cad Ter Ocup UFSCar. 2015;23(1):186-96.

5. Athayde V, Hennington EA. A saúde mental dos profissionais de um Centro de Atenção Psicossocial. Physis. 2012;22(3):983-1001. 
6. Bueno M, Macêdo KB. The clinic psychodinamic at workplace: from Dejours to Brazilian Researches. ECOS Estud Contemp Sub. 2012;2(2):306-18.

7. Dejours C. Alienação e clínica do trabalho. In: Lancman S, Sznelwar LI, organizadores. Christophe Dejours: da psicopatologia à psicodinâmica do trabalho. Rio de Janeiro: Fiocruz; 2011. p. 225-86.

8. Moraes RD. Estratégias de enfrentamento do sofrimento e conquista do prazer no trabalho. In: Merlo ARC, Mendes AM, Moraes RD. O sujeito no trabalho: entre a saúde e a patologia. Curitiba: Juruá; 2013. p. 175-86.

9. Azevedo APF, Figueiredo VCN. Pleasure and mental suffering experience at a Center of Psychosocial Care. Rev Psicol Organ Trab. 2015;15(1):30-42.

10. Ferreira JB. Análise clínica do trabalho e processo de subjetivação: um olhar da psicodinâmica do trabalho. In: Mendes AM, Merlo ARC, Morrone CF, Facas EP, organizadores. Psicodinâmica e clínica do trabalho: temas interfaces e casos brasileiros. Curitiba: Juruá; 2010. p. 122-36.

11. Nardi HC, Ramminger T. Modos de subjetivação dos trabalhadores de saúde mental em tempos de reforma psiquiátrica. Physis. 2007;17(2):265-87.

12. Ghizoni LD, Mendes AM. Devices for clinical listening of recyclable material collectors' suffering in their work. Contextos Clín. 2014;7(1):15-26.

13. Giongo CR, Monteiro JK, Sobrosa GMR. Psychodynamics of work in Brazil: systematic review of literature. Temas Psicol. 2015;23(4):803-14.

14. Mendes AM, Araújo LKR. A clínica psicodinâmica do trabalho: o sujeito em ação. $1^{\mathrm{a}}$ ed. Curitiba: Juruá; 2012.

15. Martins SR, Mendes AM. A clínica da psicodinâmica no trabalho. Rev Psicol Organ Trab. 2012;12(2):171-84.

16. Dejours C. Subjetividade, trabalho e ação. Rev Produção. 2004;14(3):27-34.
17. Dejours C. A loucura do trabalho. 6ed. São Paulo: Oboré; 2015.

18. Bardin L. Análise de conteúdo. $1^{\mathrm{a}}$ ed. São Paulo: Edições 70; 2011.

19. Brasil. Ministério da Saúde. Resolução nº 466, do Conselho Nacional de Saúde. Brasília, DF: Ministério da Saúde [internet]; 2012 [citado 10 jan 2018]. Disponível em: http://conselho.saude.gov. br/ultimas_noticias/2013/06_jun_14_publicada_ resolucao.h̆tml

20. Mendes AM. Trabalho e saúde: o sujeito da emancipação e servidão. $2^{\mathrm{a}}$ ed. Curitiba: Juruá; 2008.

21. Faria RMOD, Leite ICG, Silva GAD. O sentido da relação trabalho e saúde para os assistentes em administração de uma universidade pública federal no estado de Minas Gerais. Physis. 2017;27:541-59.

22. Gemma SFB, Rojas MF, Soares MJB. Agentes de limpeza terceirizados: entre o ressentimento e o reconhecimento. Rev Bras Saúde Ocup. 2017;42:1-10.

23. Glanzner CH, Olschowsky A, Kantorski LP. Work as a source of pleasure: evaluating a Psychosocial Care Center team. Rev Esc Enferm USP. 2011;45(3):716-21.

24. Ghizoni LD, Mendes AM. Mobilization of a collective of waste pickers: practice in Psychodynamic Cooperation Clinic. Cad Psicol Soc Trab. 2014;17(2):206-23.

25. Mendes AM. Da psicodinâmica à psicopatologia do trabalho. In: Mendes AM, editor. Psicodinâmica do trabalho: teoria, métodos e pesquisa. São Paulo: Casa do Psicólogo; 2007.

26. Ballarin MLGS, Carvalho FB. Ferigato SH, Miranda IMS, Magaldi CC. Psychosocial care center: convergence between mental and collective health. Psicol Estud. 2011;16(4):603-11.

27. Gama PL, Mendes AMB, Araújo JP, et al. Reframing suffering: clinical work at a teaching hospital. Rev Laborativa. 2016;5(1):38-63. 